\title{
Harnessing the Wild Horses of Neurosis: Contemplative Performance Pedagogy
}

\section{Lee Worley}

Professor Emerita, Naropa University, 2130 Arapahoe Ave, Boulder CO 80302, USA

\section{KEYWORDS}

Improvisation for actors

Contemplative Performance

Meditation

Buddhism

\section{ABSTRACT}

Developing organizing principles for training actors in improvisational forms, Worley turns to Asian philosophies and Tibetan Buddhism for contemplative approaches and some hints at alternatives to the usual audience/actor relationship.

\section{Introduction}

Do I teach actors improvisational tools influenced by my study and practice of Buddhist meditation, or do I use theatrical improvisation as method to reveal the truths the Buddha taught? When at my best, I think I do both. Buddhist meditation master Chögyam Trungpa presented theatre as a way to bring dharma to Western consciousness. I thought so too for a long time but failed at making performances of influence. Instead, coupled with my Western acting training, the principles of Buddhist psychology and philosophy offered me a way to train performers in contemplative approaches to life and art.

In the West we seem to have fewer aesthetic and organizational principles built on natural laws than do Asian cultures. There are some religious examples like Father, Son and Holy Ghost and some from sports like 'On your mark, get set, go'. Also there were once maxims now largely retired from use: 'A stitch in time saves nine', or 'as the crow flies' and all sorts of psychological models such as Elisabeth 
Kübler-Ross's five stages in facing the diagnosis of a terminal illness: denial, anger, bargaining, depression and acceptance.

But none of these are as embracive as, for example, the Asian principle of Heaven, Earth and Human - heaven being above, earth below and human joining these two great realities. These principles can be applied to an abundance of art forms and constructive projects, showing up in flower arranging, calligraphy, martial arts, governance, poetry and much more.

Influenced by my studies of Japanese dance, I used and still use the principle of Jo Ha Kyu (Japanese for beginning, middle, end) in performance, improvisation and life. Those three syllables carry much more nuanced specificity than their English translation. Whereas English merely marks out a timeline, Jo $\mathrm{Ha}$ Kyu conveys the quality, the sensation, or the experience of the situation. Jo is described as an orderly beginning, Ha initiates breaking away, and Kyu suggests a rapid conclusion. Yoshi
Oida, in his book The Invisible Actor, (2008, p. 30-39), has an extensive description of Jo Ha Kyu in performing.

Using an analogy, we might think of this framework in terms of archery. Jo is the set-up, the placing of the arrow on the bow, lining up one's body and sighting the target. Ha then is the pulling back of the bow string, lifting the bow and aiming the arrow and finally Kyu is the arrow as it flies. Jo and $\mathrm{Ha}$ are in the hands of the archer but Kyu is not. Not only is Kyu a rapid conclusion but it carries the action to a more uplifted plane. It is difficult to think of Western analogies that carry such profundity.

The four seasons illuminate some of what I'm searching for: spring being the birthing time, summer the flowering, fall the bearing of fruit and winter the resting, renewal or retreat. Yet even though this comes close, in the United States we do not follow this rhythm. Hardly universal, fall has become our birthing or beginning, win- 
ter our growing and developing, spring the fruition and summer the letting go. This is likely due to the way educational systems from kindergarten through higher education structure time. Our cultural life - concerts, movies and the like - also follows this pattern.

One frame that seems rather universal, embraced by both East and West, is that of Rites of Passage. Here the principles of separation, transition and integration (or reintegration) are ripe with resonance and truth, at least for the human realm, even more so when using the word 'liminal' thus pre-liminal, liminal, postliminal. But to me the words feel inorganic, fleshless until covered with a particular culture's trimmings.

Which brings me to the Four Karmas or Four Actions, a framework from the Tibetan Vajrayana tradition. I learned about the Four Karmas from meditation master Chögyam Trungpa, my first Buddhist teacher. Little seems available in
English to provide information about the origin or spiritual use of this frame and Trungpa didn't elucidate the origins. In my research for this article, I asked Dr Karl Brunnhoelzl and Dr Judith Simmer-Brown, both scholars of Tibetan Buddhism, to point me to sources on the origins of the Four Karmas but they were unable to offer any textual material. I did uncover two magazine articles by Westerners, one a psychologist and the other a businessman turned meditation teacher. Both referred to the four as steps in resolving personal situations: one emotional, one in the workplace. Neither resonated with my understanding. I got some hint of a sacred quality when watching a YouTube clip of Jetsun Khandro Rinpoche (Jetsun, 2004). The clip appeared to be an answer to a student question. Khandro Rinpoche spoke of the karmas as steps in an empowerment ritual process for that individual to develop confidence.

Trungpa implied that one might view 
these karmas both as four distinct enlightened actions or activities and as four progressive parts of a single action or event. These four are: pacifying, enriching, magnetizing and destroying. They are related to four of the five Buddha Families. Perhaps you could say that they are the basic activity of these Buddha Families which connect on the material plane with the four elements of water, earth, fire and wind respectively. They also have a flip side, a negative aspect called the Four Maras.

'Mara' is a Sanskrit word meaning, 'the evil one'. In Buddhism, maras personify habitual patterns of ego-clinging which prevent our becoming enlightened. In Trungpa's Mudra Theater Group we referred to them as the "wild horses of neurosis'. Raised under the influence of Trungpa, and based on his teaching from a booklet called Secret Beyond Thought: The Five Chakras and the Four Karmas (1991) I have created my own interpretation and take responsibility for its usage in this improvisational framework.

\section{The Four Karmas in Acting Training}

Originally it wasn't my intention to bring this Buddhist notion of the four karmas into my acting training. An improvisational form for four actors that I learned from one of my acting teachers vaguely resonated with the four karmas idea and so I called it that. Only by working with students and actors over time did the link between the exercise and karmas clarify and become shapely, finding its way into my contemplative performance pedagogy.

The problem: My acting school training centred primarily on scene study. Short excerpts from plays, usually scenes with two people which included some build in emotional intensity. My improvisational experience came from work with the Open Theater. There, our early improvisations were clever and sometimes witty in the style of Chicago's Second City. However, 
we soon became interested in exploring a more physical vocabulary. Words, where needed, were secondary to gesture or sound and movement expressions of socalled inner states of being. So, when I started teaching improvisation, conversations would drearily drag on and on or often caricatures would just go for laughs. I hadn't many tools to assist actors in improvising characters who talked normally and interacted truthfully within the moment.

\section{How I Hoped the Four Person Exercise}

\section{Would Support Improvisation}

- to assist actors in understanding the purpose and significance of intentions or objectives; the active verb quality of action

- to discover that words can say one thing and yet allow the underlying objective to be another thing

- to learn how to keep steadily pursuing an intention while changing approaches when necessary
- to become comfortable engaging in heightened or intense but 'normal' conversation

- to support listening and speaking without knowing where it will lead

- to practice supporting one's improv partner(s) while not abandoning one's own objective

- to build on the 'yes, and' approach

- to learn to avoid the dreary or banal, or falling into discursive chat

Finally, since I was teaching improvisation, I wanted the actors to practice quickness in applying all of the above. The exercise I named 'The Four Karmas' was my solution to communicating these basic performance skills.

\section{The Four Person Improvisation Exer- cise}

In discussing the mechanics of this exercise, I will be moving between speaking both of the actor's responsibility and of the 
character that he or she chooses to play. This gets confusing. Sometimes actor and character have the same task, but not always. I will therefore call it the actor's 'task' and the character's 'intentions'. Each of the four actors has a specific task, while his or her character can have a number of smaller intentions on the way to accomplishing the actor's task.

Actor One's task is to set up where the action will take place and become involved in an activity. The activity should be one that is fully engaging to the character, something difficult to put aside. This having been established, Actor Two enters with the task of making a relationship with the first character. This can be done in many ways, some friendly, some antagonistic.

The mark of Actor Two's success is when the first character abandons his or her engagement/activity and shifts into relationship with Actor Two's character. Then Actor Three's task is to pull apart characters one and two. To state this an- other way, character three's job is to make a relationship bond with one of the first two characters. Lastly, Actor Four must be aware of timing so that this new relationship, plus whatever is happening to the odd one out, is truly established because it is Actor Four's task to clear all actors from the stage. For an extended description of the Four Karma exercise, see my book Coming From Nothing: the Sacred Art of Acting (2001, p. 94).

\section{What Makes This a Contemplative Exer- cise or Expression?}

The way each of the four actors approaches the situation, develops a character and then executes his or her character's intentions has the potential to train a contemplative approach or reveal a dharmic aesthetic. To be effective the actor's execution of the task and his or her character's intentions and methods must be wholeheartedly straightforward and honestly embodied. The actors must have confidence that, act- 
ing with and from this sincerity, the results will be viscerally authentic.

In his book, The Future is Open:

Good Karma, Bad Karma, and Beyond Karma (2018), Trungpa writes:

If there are two choices, one is ahead of you, right in front of you and the other choice is slightly offcenter. There may be ten or twelve hundred choices, but there is one choice waiting for you on the road (Trungpa, 2018, p. 145).

How often, due to our confusion, or the urge to keep the audience entertained, or a need to be liked, or a fear of looking stupid, have we, rather than being precisely in the moment, made the trite, or the clever, or the sidestepping choice instead of the scary, but clearly lit one? Trungpa continues:

In our ordinary life situations, we have to open ourselves and investigate and see and then make a commitment. Without choice, there would be no leap and no moment of letting go at all. Because of choice, therefore, there is a moment of leap, and letting go happens. So making choices in the present moment is not particularly comforting, blissful, or easy. On the other hand it could be inspiring (Trungpa, 2018, p. 146).

For those of us who perform, acting is our 'ordinary life' or at least in this contemplative performance training we must master living well so that we can truly represent it on the stage, while being witnessed, and still be in the moment, on the spot. Fearlessly! It is this authenticity that underlies the purpose and challenge of using the framework of the Four Karmas.

\section{What the Karmas Provide to the Improvisation}

\section{Pacifying}

For Actor One, setting the stage requires full embodiment and attention to detail, truly inhabiting a specific place (often with few props or set pieces to assist). Performing an activity requires the actor's (as well as his or her character's) full commitment and concentration. For these purposes 'pacify- 
ing' could be said to be 'making things into a peaceful environment' (Trungpa, 1991, p. 25). The actor/character is alone, engaged in something important. Pacifying doesn't necessarily mean tranquil; the character might be hastening to get the floor painted or fearful of discovery while searching for a precious jewel, but there is a quality of taming the space that is the ground upon which future action will be played. Failure to pacify might mean that the activity is so inactive or artificially acted that the scene is simply dull, or the importance or significance of the activity might be so trivial that it isn't engaging enough to keep the character from dropping it, upon Actor Two's arrival.

In setting the scene, a lack of enacted detail about where the character is located can cause confusion or misinterpretation, creating anxiety for the next actor as well as for the audience. Choosing to create easily understandable places that are not too idiosyncratic or busy with ob- jects is important. A sunny day on the beach might be more fruitfully pacific than a farmers' market, for example. After all, it is the actor being featured, not the mime or set designer. Simplicity is a contemplative value here. Having said this, however, one of my most indelible memories is of a Four Karmas scene among a strange breed of creatures living on an unknown planet. Nothing is set in stone in this work.

Upon the arrival of Actor Two, Actor One needs to continue strong investment in his or her character's intention and simultaneously maintain an actor's awareness of the new story thread that character two presents. Additionally, Actor One must be ready to accommodate unexpected differences like, due to Actor/(character) Two's projection, discovering that one is in a hotel when one thought one was in one's bedroom or that one is making breakfast when one thought it was a midnight snack.

The 'Yes, and...' approach of improvisational theatre begins to apply here. Ac- 
tor Two should honour the physical elements and arrangement of the scene even if it has been transformed. For example, if character two enters a hotel room which in character one's mind is her bedroom, the full-length mirror, if it had been indicated in some way, is still where Actor One located it. On the other hand, if character two announces that the babysitter is on her way up, character one is obliged to make a choice that justifies such an announcement rather than informing the entering character that there is no child or that she has no idea who character two is.

Of course, there can be exceptions. Character two may have absent-mindedly entered the wrong bedroom, but probably in the spirit of pacifying, Actor/(character) One is wise to maintain that for whatever reason what she is doing is too important to stop and thus the harried hunt for the jewel suddenly must become a hunt for the missing baby blanket without which Janiekins will not sleep.
Trungpa concludes his definition of pacifying with, '[pacifying is] connected purely with not raising any controversy of discriminating the experience of that as opposed to this, but instead accepting with the wisdom of spontaneity and working with that' (Trungpa, 1991, p. 26).

\section{Enriching}

Upon the entrance of Actor Two, the Karma becomes Enriching which for purposes of the improvisation involves character two making a relationship with character one. Actor Two, if this is a study in contemplative approaches, needs to understand that on a certain level, nothing is needed. The scene is already enriched by adding an additional character and consequent plot twist. Trungpa writes, 'it [enriching] is connected with just being and producing' (Trungpa, 1991, p. 26). I've observed that without the Four Karmas frame, a habitual tendency among actors is to bring much too much into the situation. As Trungpa 
writes, with regard to the situation of increasing wealth, of whatever sort:

increasing wealth is the action of splendor, the action of tremendous dignity connected with wealth. Wealth is not accumulated by the frivolous quality of any particular action, but it just grows and develops. And that particular situation is developed by being still, peaceful (Trungpa, 1991, p. 26).

This is extremely important if the

Four Karmas are to lead to action that furthers a satisfaction for all concerned. Western approaches to performance are not accustomed to the ideas of dignity or splendour implied in this model. 'The babysitter is on her way up' forces so much onto the scene that many possibilities are forever blocked. Who knows what might happen if instead Actor/(character) Two's entrance began simply with a knock on the door? A liminal space.

A cognitive therapist friend once described an incident with a child she had been observing. The child was withdrawn and uncommunicative and sat playing with some blocks by himself away from the other children who ignored him. Her son, however, after some time came silently over to the boy, quietly sat down near him and watched him play. After some more time he offered the boy a block from the pile. Hesitantly the boy took it. Then, after another while, another block. Soon they were building together.

The contemplative exploration for Actor Two is to investigate a potential relationship with character one. If character one is truly engaged in his or her activity, relationship isn't the first priority. While the announcement that the babysitter is on her way up doesn't offer many possibilities, staggering in with a bloody nose might cause character one to briefly stop what (s)he is doing, but it isn't necessarily going to lead to much relationship beyond an offer of Kleenex and ice pack. Strangely, enriching is the quality of surrendering, which requires a confident presence, a humbleness that has self-worth as its core. 
Actors may argue that dramatic action has to move quickly or the audience will be bored, that deep relationship takes too long to develop, but the easy, the slick or the obvious is less enriching than taking the time needed. A director could remind the actor that this isn't about a performance; it is about learning authenticity in improvisation.

Relationship needn't be about love or niceness in this exercise. Nothing is more bonding than a heated argument or giving help if it is needed and asked for. But Actor One isn't responsible for helping Actor Two fulfil his task. Quite the opposite. If it organically happens, this is fine. Often, however, our conventional habit of 'helping' causes Actor One to drop his objective. If the urgency to find the baby blanket or finish painting the floor is really there for character one it may take some skill on Actor Two's part to achieve the relationship task, that is, for character two to find a successful intention. I consider this ability to maintain intention but vary methods a contemplative talent available only to someone with a flexible mind.

\section{Magnetizing}

For Actor Three, Magnetizing, the first challenge is right timing. If (s)he enters too soon or too late and either the bond isn't yet secure or the relationship is too well established there will be no challenge, no drama. Magnetizing means that Actor Three's character must pull apart (magnetize) character one from character two, or in other words, must make a relationship with either character one or character two, upsetting what was until then a rather simple plot. Trungpa writes, 'Magnetizing means drawing everything into our situation like a magnet' (Trungpa, 1991, p. 27).

In many ways, Actor Three's job is a heightened version of Actor Two's. The emphasis here is in the degree of fullness or grandness of the situation. Trungpa puts it like this: 'All the life situations begin to 
come to us' (p. 28). The third karma invites negative as well as positive actions to colour the scene. Conflicts of all kinds may be attracted to the story - passion, jealousy, anger or territoriality. As Trungpa humorously remarks, 'It doesn't seem to be all that simple once we get into the details of it - which is true of a lot of things' (Trungpa, 1991, p. 28).

By this point in the improvisation, if it is going well, there is no way to predict what will happen. Here, for all three actors, keen awareness of the whole space, the necessity to listen, to adjust, to stay in character, to maintain or redefine intention will all be in the mix. All are aspects of good improvisation and principles for leading a contemplative life. Even the conflicting emotions which are often taboo or considered antithetical to living mindfully can be seen here as playful energies, colourful threads in the pattern of the story or the fabric of living.

\section{Destroying}

Which brings me to the fourth karma, Destroying. Beyond the obvious connotations lie subtle nuances. The seed is destroyed so that the sprout can grow; the night is destroyed by the coming of day and all improvisations must end. Actor Four enters and is tasked with clearing the stage. The timing of the entrance is once again important. If the three character scene goes on and on it will surely become repetitive or banal; if it doesn't have a chance to develop there won't be much to destroy. All this is simple showmanship. The more subtle or compassionate action is how to destroy skilfully, cleanly. A Buddhist saying is that compassion destroys whatever needs to be destroyed and cares for whatever needs its care. In Trungpa's words, '...the process of action or karma is connected with something real, the reality of the situation rather than some imaginary quality' (Trungpa, 1991, p. 29).

Actor Four could enter shouting 
'Fire! Fire!' which might solve the problem of removing the characters from the room that is about to burn. However, the suggestion that the destruction be part of the reality of the situation provides an improvising challenge both for Actor Four and for the other three. Trungpa suggests that destruction is more like pruning than chopping down. Translating this into an approach for Actor Four suggests entering with great openness, perhaps even fewer ideas of plot than Actors Two and Three came in with, and once inside the action, tuning in to where the group energy is headed and helping it get there. This is a skill of great meditation masters. Trungpa speaks often of 'auspicious coincidence' of how causes and conditions come together. You don't have to do anything; the practice is to stay awake in the moment and allow. The master's task is to find where the student's energy is going and help clear a channel for him or her to move in the direction of enlightenment: the destruction of ego.

\section{And What About the Audience...?}

So far this discussion has centred on the actors' approaches to the improvisation via the karmic actions and the improvisational style that this creates. Beyond this is the impact these circumstances have on the audience which, after all, is why one creates improvisations. Here are a few thoughts on how this karmic progression might play out for the audience.

\section{Pacifying}

The audience comes to watch an improvisation. They come from their day of work or family or digital news broadcasts. They come with agitation or fatigue and a wish to be entertained. Pacifying means providing them a time of peace, clearing away the external cares of the world and allowing them to settle, breathe and adjust to what is about to be offered. Without this time of settling, all performing will feel as if 
thrust upon them and, consciously or not, their reaction may be one of defence. A good public speaker pauses before beginning to speak. He may say, 'Good evening'. He might look around at his audience or begin with a joke or small personal anecdote. All this is the pacification necessary for relaxing (reassuring) the audience. Theatrical pacifying is often provided by means of pre-show music or a slow dimming of the lights, but here it is the action of the improvisation itself which pacifies.

\section{Enriching}

The audience waits for what is going to happen. Anticipation is a sort of liminal space that precedes enrichment so that it truly enriches both the improvisation and the audience. Then richness needn't be dumped out all at once, like saturating young plants with Miracle Grow. There is compassion in a mindful emergence of enriching. Any entertainment adds richness, but contemplative enriching has a quality of allowing the audience to come part way towards the action. As Trungpa remarked to his theatre students, 'A full moon is nice, but a crescent moon might be more intriguing'.

Or, as my theatre director Joe Chaikin once said, 'A good soprano can sing very high notes, a great soprano, when she sings those high notes, makes you feel that she could sing even higher ones'. In Secret Beyond Thought, Trungpa writes,

It is connected with just being and producing. It is rather like a tree which stands constantly still, day and night, day and night, day and night; and finally it grows, it gradually grows and produces fruit. Very rich fruit comes out of it (Trungpa, 1991, p. 26).

\section{Magnetizing}

Because the audience is enriched, there is satisfaction in the development of the improvisation, not dullness. It is like having had such a good meal that one doesn't want dessert, but...well, perhaps a cognac 
would be lovely. Something sort of intoxicating, seductive, maybe even edgy or harsh to top it off. By contrast, Western climaxes tend toward bigness: car chases, sex scenes, explosions or murders. Of course, all depends on the particular improvisation, but there is a tendency toward humour here as well as a display of the multifaceted array of human emotions magnetized by the situation and the three actor/characters who find themselves in it.

\section{Destroying}

Finally there must be some ending, some closure. Early movies used to display 'The End' on the screen. Destroying means the event is concluded, final. Western culture shies away from endings, thus causing a continual middle-ness, a sort of flat line to reality. Ending is necessary so that a new, or next, event can begin with freshness. In the case of contemplative improvisation, destroying could be considered an act of compassion to the audience, not to aban- don them but to release them. Curiously we often rely on the curtain call as our closure, not on the show itself. We destroy the event by thanking the actors. Bearing in mind Trungpa's metaphor of pruning, or the free flight of the arrow, the final action can be and feel organically satisfying.

\section{Kyu}

Like practicing headstands to learn something about standing on two feet, or standing still to better appreciate movement, this four-part structured improvisation's usefulness could help us recognize our Western action habit of beginning by Destroying and then groping our way backwards towards Pacifying; towards peace. It might be influential in revealing a different perspective on how our actions could evolve, thereby increasing our aesthetic tool box. Beyond that, wouldn't it be encouraging to think that this alternative action flow, demanding openness and a listening core of receptivity and trust could subtly revise our 
audience's comportment as well?

At the conclusion of the Mudra Theater Conference in 1973, quite a crazy time for many of us, Trungpa provided this evocative explanation of his improvisational method:

You let loose the wild horses you've trained... I have well trained wild horses and in this particular ring I open the door. That's my only role, I open the door and let the wild horses, wild asses or wild mules, or crocodiles or whatever, let them in and relate with the whole thing. You might find this extremely unorganized and it does not keep up with the so-called institutionalized programs that have the ... proper things happening, but somehow I feel by doing such things that we have more chance to relate with the spontaneous situation of experiential theater (Trungpa, 1973).

In a world so hell-bent on self-destruction it is daringly optimistic to imagine that this appreciation of the liminal in approaching performing and performance will find traction or incite radical change, but maybe it could reorganize our own frames of refer- ence to more fully include simplicity, authenticity and spaciousness, and at least increase the chances of relating to our lives as spontaneous play.

\section{$\underline{\text { References }}$}

Khandro, J. (2004) On Intention, www.khandrorinpoche.org>tag $>$ fourkarmas

Kübler-Ross, E. (2019) On Death and Dying: What the Dying Have to Teach Doctors, Nurses, Clergy \& Their Own Families. New York: Scribner

Oida, Y. \& Marshall, L. (2018) The Invisible Actor. London: Bloomsbury Methuen Drama

Trungpa, C. (1991) Secret Beyond Thought: The Five Chakras and the Four Karmas. Halifax: Vajradhatu Publications. , (2018) The Future is Open: Good Karma, Bad Karma, and Beyond Karma. Boulder: Shambhala

of the Mudrom an unpublished transcript Boulder, Colorado, February, 1973.

Worley, L. (2001) Coming From Nothing: the Sacred Art of Acting. Boulder: Turquoise Dragon Press 